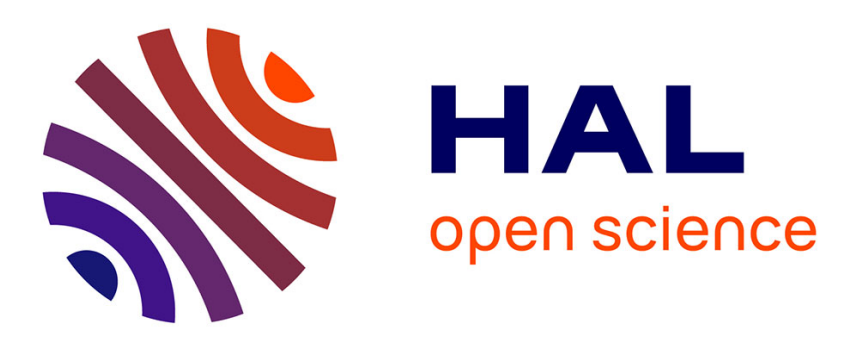

\title{
ELECTRONIC PROPERTIES OF PURE AND INTERCALATED 2H-NbS2 BY MEANS OF PHOTOACOUSTIC SPECTROSCOPY
}

P. Bechthold, R. Manzke, R. Schöllhorn

\section{- To cite this version:}

P. Bechthold, R. Manzke, R. Schöllhorn. ELECTRONIC PROPERTIES OF PURE AND INTERCALATED 2H-NbS2 BY MEANS OF PHOTOACOUSTIC SPECTROSCOPY. Journal de Physique Colloques, 1983, 44 (C6), pp.C6-159-C6-163. 10.1051/jphyscol:1983624 · jpa-00223183

\section{HAL Id: jpa-00223183 https://hal.science/jpa-00223183}

Submitted on 1 Jan 1983

HAL is a multi-disciplinary open access archive for the deposit and dissemination of scientific research documents, whether they are published or not. The documents may come from teaching and research institutions in France or abroad, or from public or private research centers.
L'archive ouverte pluridisciplinaire HAL, est destinée au dépôt et à la diffusion de documents scientifiques de niveau recherche, publiés ou non, émanant des établissements d'enseignement et de recherche français ou étrangers, des laboratoires publics ou privés. 


\title{
ELECTRONIC PROPERTIES OF PURE AND INTERCALATED 2H-NbS 2 BY MEANS OF PHOTOACOUSTIC SPECTROSCOPY
}

\author{
P.S. Bechthold, R. Manzke and R. Schö11horn* \\ Institut für Festkörperforschung der Kexnforschungsanlage Jülich, \\ Postfach 1913, 5170 Julich, F.R.G. \\ *Anorganisch-Chemisches Institut, Universität Minster, Gievenbecker Weg 9-11, \\ 4400 Minster, F.R.G.
}

\begin{abstract}
Résumé - La technique photoacoustique est utilisée pour obtenir les spectres de réfllectivité d'échantillons métalliques. Nous présentons des résultats obtenus pour $2 \mathrm{H}-\mathrm{NbS} 2$ pur et pour ses composés intercalaires comprenant du cuivre ou de la pyridine. Nous montrons qu'un modèle de bande rigide rend compte des propriétés électroniques de $\mathrm{NbS}_{2}$ (Pyr) 0,5. Dans le cas de $\mathrm{NbS}_{2} \mathrm{Cu}_{\mathrm{X}}$ ( $\mathrm{x}=0,4$ et $0,6)$ ce modéle n'est plus valide en raíson de l'augmentation du couplage entre les plans induite par le cuivre.
\end{abstract}

Abstract - The photoacoustic technique is utilized to obtain reflectivity spectra of metallic samples. We report reflectivity data up to $6 \mathrm{eV}$ of pure and pyridine and copper intercalated $2 \mathrm{H}-\mathrm{NbS}_{2}$, the latter reported for the first time. We find that for $\mathrm{NbS}_{2}$ (Pyr) 0.5 the electronic properties are reasonably approximated by a rigid band picture. For $\mathrm{NbS}_{2} \mathrm{Cu}_{\mathrm{x}}(\mathrm{x}=0.4$ and $0.6)$ an increased interlayer interaction makes this model insufficient.

$2 \mathrm{H}-\mathrm{NbS}_{2}$ forms a metal with a layered hexagonal structure. It can be intercalated by introducing atoms or molecules into the octahedral and tetrahedral holes of the interlayer van der Waals gap $/ 1 /$. Thereby the interlayer spacing is expanded, superstructures may be formed and stacking orders may change. Copper, e.g., occupies tetrahedral holes and the $\mathrm{NbS}_{2}$ layers are slightly shifted with respect to each other resulting in a $2 \mathrm{H}-\mathrm{MbS}_{2}$ structure $/ 2-4 /$. Due to the intercalation the electronic properties of the compound are modified by a charge transfer from the guest species to the $\mathrm{NbS}_{2}$ layers, where the additional charges occupy empty states in the half-filled ' $\mathrm{d}_{z} 2$ "'-conduction band.

We are using photoacoustic spectroscopy (PAS) in order to determine the electronic properties of pure and pyridine and copper intercalated $2 \mathrm{H}-\mathrm{NbS}_{2}$. PAS completes the conventional spectroscopic techniques (e.g. absorption, reflection (RS), and electron energy-loss spectroscopy (EELS), because a minimum sample preparation and no thin films are required, and it is insensitive to the crumpled surfaces of these layered compounds which make reflectivity measurements more difficult $/ 5 /$.

The $2 \mathrm{H}-\mathrm{NbS}_{2}$ single crystals were prepared from the elements by vapor phase transport with iodine in a temperature gradient of $970-980^{\circ} \mathrm{C}$. The 
intercalation compound $\mathrm{NbS}_{2}\left(\mathrm{C}_{5} \mathrm{H}_{5} \mathrm{~N}\right)_{0.5}$ was synthesized by direct thermal reaction of $\mathrm{NbS}_{2}$ with pyridine /6,7/. The copper phases $\mathrm{Cu}_{\mathrm{x}} \mathrm{NbS}_{2}(\mathrm{x}=0.4$ and $\mathrm{x}=0.6)$ were prepared by electrochemical intercalation of copper at ambient temperature. Single crystal electrodes of $2 \mathrm{H}-\mathrm{NbS}_{2}$ were subject to cathodic reduction under galvanostatic conditions at low current densities in a $\mathrm{Gad} / \mathrm{CH}_{3} \mathrm{CN}$ electrolyte. The stoichiometry of the samples was calculated from the ionic charge transferred per formula unit $\mathrm{NbS}_{2}$. The samples are susceptible to slow oxidation by $\mathrm{O}_{2}$ under formation of $\mathrm{CuO}$ and $\mathrm{NbS}_{2}$ as the final products.

$\mathrm{NbS}_{2}$ and $\mathrm{NbS}_{2}(\mathrm{Pyr})_{0.5}$ show good cleavage parallel to the layers.

The materials could therefore, be studied by photoacoustics, absorption $/ 4 /$, and EELS $/ 8 /$. The cleavage of the Cu-intercalates is, however, considerably poor. Thus EELS and absorption spectroscopy on these materials is impossible because of the lack of adequately wide thin films.

The saturation of the photoacoustic signal of optically and thermally thick samples $\left(1 \gg 1 / \beta\right.$ and $1 \gg \mu_{S}$; with $1=$ sample thickness, $\beta=$ optical absorption coefficient and $\mu_{\mathrm{s}}=$ thermal diffusion length of the sample) opens up the possibility of comparing directly PAS- and RS-spectra. According to the Rosencwaig-Gersho theory the PAS-signal in the above limit is given by
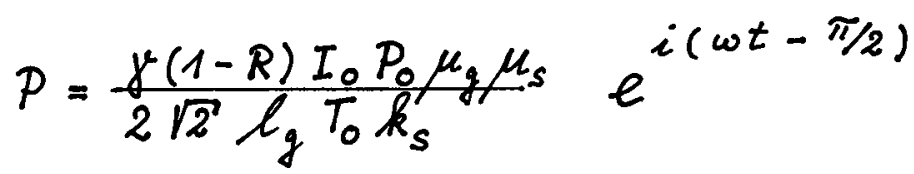

with the assumption $1 / \beta^{2}<<\mu^{2} / 2$, generally correct for metals. After normalization with respect to the spectral output of the lamp the reflection coefficient of the sample $\mathrm{R}$ is the only wavelength dependent quantity. Therefore, equation (1) can be simplified as follows

$$
\text { (2) } P=\text { const } \cdot(1-R(\lambda)) e^{i(\omega t-\pi / 2)}
$$

from which the relative reflectivity can be determined. The constancy of the phase shift of the signal with respect to the modulated light source can be utilized to test whether signal saturation holds in the complete spectral range.

Fig. 1 shows a comparison of the reflectivity spectra of pure $2 \mathrm{H}-\mathrm{NbS}_{2}$ as measured by three spectroscopic methods, namely PAS, RS, and EELS. The RS-data are taken from ref. $/ 5 /$, whereas the EELS curve is derived from a Kramers-Kronig analysis of the energy-loss function /8/. The PAS and RS data are normalized with respect to the absolute value at $1.0 \mathrm{eV}$ of the EELS-measurement. The EELS result exhibits a poor energy resolution of $0.5 \mathrm{eV}$ as compared to the optical measurements. Although it is therefore less structured, we find a good qualitative agreement regarding all three techniques.

Fig. 2 shows PAS-spectra of the investigated compounds. In the low energy regime the spectra exhibit a sharp plasma edge with a reflectivity minimum $M$ which is due to the collective excitation of the electrons in the " $\mathrm{d} z$ "--band (plasmon loss). This spectral range is most strongly influenced by the 


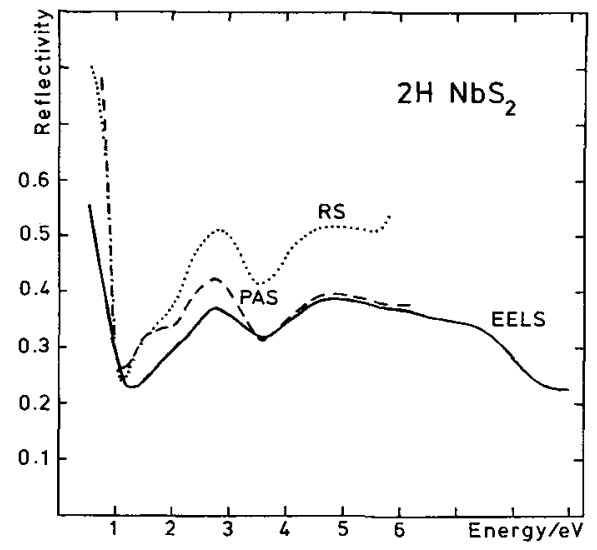

Fig. 1 Comparison of the reflectivity spectra of pure $\mathrm{NbS}_{2}$. The spectra are measured by photoacoustic - (PAS), reflection - (RS) $/ 5 /$, and transition electron energy-loss (EELS) spectroscopy $/ 8 /$.

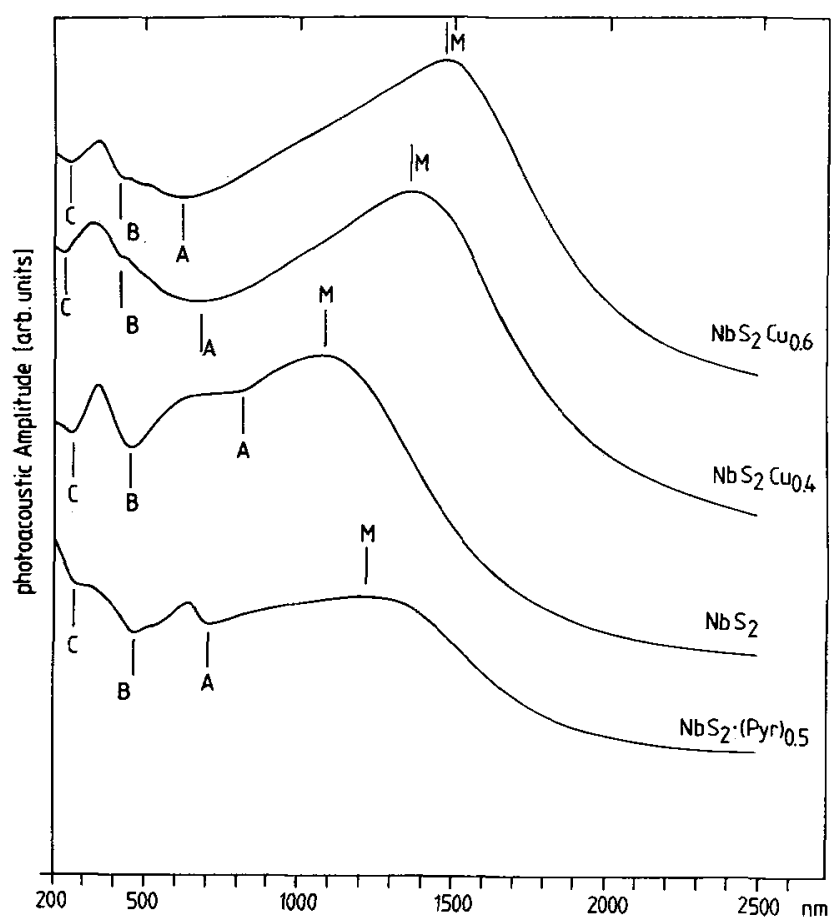

Fig. 2 PAS-spectra of pure and intercalated $\mathrm{NbS}_{2}$. For the assignments of the peaks see text and Table 1. 
intercalation and the correlated charge transfer. The structures A, B, and C at higher energies are assigned to interband transitions from the valence band to empty states of the conduction band.

The shifts in the spectral features of the intercalated compounds with respect to the pure $\mathrm{NbS}_{2}$ are dominantly caused by a charge transfer from the guest species to the $\mathrm{NbS}_{2}$ layers. Due to the weak van der Waals interaction between the layers a "rigid band model" was proposed to describe the electronic properties of the intercalation compounds $/ 9 /$. In this model the density of states of the host remains unchanged upon intercalation and the initially half-filled " $\mathrm{z} z$ "-band is successively filled by the electrons transferred from the guest. This causes a slight increase of the Fermi energy. The consequences of this simple model are (We use the notation of ref. 5): 1. Reduction of empty "d 2 "states and thus a decrease of the corresponding plasmon energy.

2. Increase of the $p(d)=d z^{2}$ transition energy.

3. Decrease of the $d_{z} 2 \rightarrow d(p)$ transition energy.

4. The $p(d) \leftrightarrow d(p)$ transition energy remains unchanged.

For $\mathrm{NbS}_{2}(\mathrm{Pyr})_{0.5}$ these conditions are realized, when we assign the spectral features to the transitions as given in table 1. If intercalation does not change the effective mass of the " $\mathrm{d} z$ "-electrons (which for $\mathrm{NbS}_{2}(\mathrm{Pyr})_{0.5}$ is consistent with EELS measurements /8/) the charge

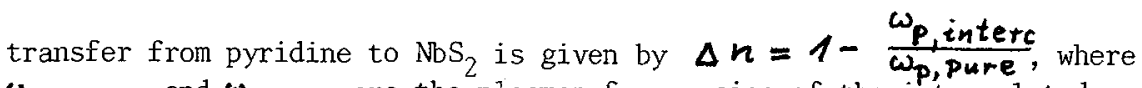
$\omega_{\mathrm{p}}$ interc and $\omega_{\mathrm{p}}$,pure are the plasmon frequencies of the intercalated and the pure $\mathrm{NbS}_{2}$, respectively. For $\mathrm{NbS}_{2}(\mathrm{Pyr})_{0.5}$ the reflectivity minimum is shifted by $0.14 \mathrm{eV}$ to smaller energies. This corresponds to a charge transfer of $(0.25 \pm 0.03)$ electrons per $\mathrm{NbS}_{2}$ molecule in good agreement with previous results $/ 8,10,11 /$.

For $\mathrm{NbS}_{2} \mathrm{Cu}_{x}(x=0.4$ and 0.6$)$ we observe considerable shifts of the interband transition energies, in disagreement with the conditions 3 and 4 stated above. This is in contrast to Beal et al. /4/ who studied $\mathrm{NbSe}_{2} \mathrm{Cu}_{\mathrm{x}}$ intercalates with lower copper content $(x=0.17)$. Our results suggest an increased interlayer interaction probably due to orbital overlap with $\mathrm{cu}$-states. Thus the electronic properties of intercalates with high copper content cannot be explained in terms of the rigid band model. However, the similarities with the other spectra in Fig. 2 allow us to suggest an assignment as given in table 1 . The plasmon is shifted to lower energies the higher the copper content, yielding a shift of $0.32 \mathrm{eV}$ for $x=0.6$. This points to an increasing charge transfer with increasing $x$. Presently the charge transfer cannot be determined. Together with the reduced cleavage the Cu-intercalates indicate a more 3 dimensional than quasi-2-dimensional metallic behaviour. 


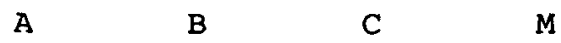

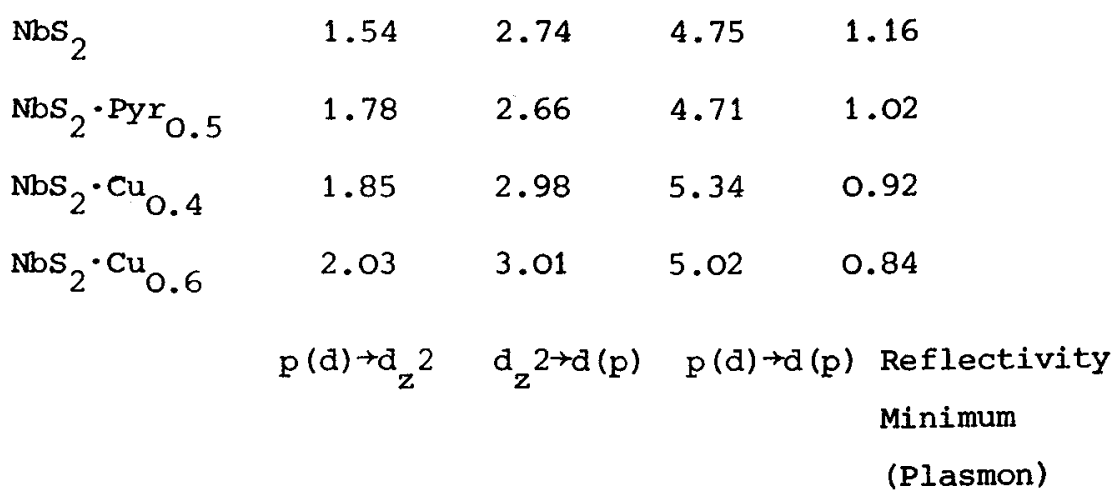

Table 1 Positions of the peaks as labelled in Fig. 2 in eV (accuracy $\pm 2 \%$ ). Notation of the transitions according to ref. $/ 5 /$.

\section{References}

1. WILSON J.A., YOFFE A.D., Adv. in Phys. 18 (1969) 193

2. KOERTS K., Acta Cryst. 16 (1963) 432

3. VAN ARKEL A.E., CREVECOEUR C., J. Less Common Metals 5 (1963) 177

4. BEAL A.R., LIANG W.Y., PETHICA J.B., Phil. Mag. 33 (1976) 591

5. PARKIN S.S., BEAL A.R., Phil. Mag. B42, (1980) 627

6. GAMBLE F.R., DI SALVO F.J., KLEMM R.A., GEBALLE T.H., Science 168 (1970), 568

7. SCHOELLHORN R., ZAGEFKA H.D., Mat. Res. Bull. 14, (1979) 369

8. MANZKE R., CRECELIUS G., FINK J., SCHOELLHORN R., Solid State Commun. 40, (1981) 103

9. BELL M.G., LIANG W.Y., Advances in Physics 25, (1976) 53

10. BEAL A.R., LIANG W.Y., Phil. Mag. 27 (1973) 1397

11. EHRENFELD E., GOSSARD A.C., GAMBLE F.R., Phys. Rev. B5 (1972) 1708 